\title{
Pseudotumor of Kidney
}

National Cancer Institute

\section{Source}

National Cancer Institute. Pseudotumor of Kidney. NCI Thesaurus. Code C123253.

A parenchymal lesion, which may appear neoplastic in origin, that results from abnormal architecture of the renal calyx. 